\section{Celebrating complexity}

This issue marks our first anniversary as Nature Biotechnology-an occasion for celebration and reflection. A glance at the past twelve months (p. 227) confirms that it is a fascinating moment to be publishing a journal of biotechnology research-the science being undertaken is rich and complex, as are the social forces that surround it.

This is not to suggest, however, that the current research environment is easy to understand and extrapolate from. As argued by Richard Strohman in his close reading and application of Thomas Kuhn's The Structure of Scientific Revolutions to contemporary biology and genetics (p. 194), we may be undergoing a Kuhnian revolution in the biological sciences, one in which the paradigm of the gene, which has stood us in good stead for 50 some odd years, will give way to models that can experimentally embrace whole cells and whole organisms, evolution and complexity. The impact this may have on biotechnology is not yet clear, although Strohman argues that biotechnology as an enterprise may have a desultory effect on the shift toward these new models, because it has a

\section{Biotech's latest wrinkle}

The robustness of the biotechnology industry was on display at a recent Hambrecht \& Quist meeting in San Francisco: A total of 27 IPOs and 47 follow-on offerings during 1996 raised $\$ 5.4$ billion in equity capital, bringing the combined market cap for all biotechnology companies to $\$ 205$ billion. Despite an overall negative performance in biotechnology stock prices, investors were encouraged by the prospect of the biotechnology drug pipeline beginning to fill. Certainly, the 7 biotechnology products that were approved during 1995 bolstered investor confidence. But a new wrinkle promises to trouble the brow of biotechnology investors and CEOs alike. The potential spoiler in biotechnology's game plan is not the FDA nor government-directed health care reform. Strangely enough, it is the free market itself.

The past year witnessed a dramatic rise in activity in the healthcare service sector. Under this broad banner march companies providing health-care information services, dialysis, home-health and nursing care, and physician practice management. They all propose to more efficiently control health care costs than their predecessors-and to deliver a healthy return to their investors. To accomplish this, they have tried growing big-attempting to link all facets of health care under very large roofs. The resulting merger and acquisition activity has created a "predator or prey" environment that yielded 87 deals worth an estimated \$14.2 billion in 1996 alone.

These monolithic companies will control whether biotechnology products are put on the formulary, suggesting that 1997 could prove to be yet another trial for the industry. The 40 or so phase III clinical trials scheduled to end this year will produce important drugs seeking to capture new markets. Just as early biotechnology companies claiming to be able to do everything could not live up to their promises, the latest generation of health-care managers haven't been able to deliver a return on investment. As a result, these companies are becoming even more conservative to bolster their bottom lines. They will not be predisposed to try innovation of any sort that costs them lots of money, as biotechnology drugs surely will. lock on resources that might be better put toward their development, and because the genetic and molecular reductionism that is its foundation cannot describe and contain complex dynamic systems.

Scientific publishing-intrinsic to the sociology of scientific research-is also facing transitional contractions. We do not portend the millennial end of paper journals, nor the end of reading for that matter, but perhaps this is because we cannot see, in the midst of "normal publishing," over the edge and into the new model, which is now under construction. We do see that the paper journals of the next publishing paradigm will be the endpoint for a process that will be conducted almost exclusively electronically, with significant repercussions for peer review, authorship, and publishing house procedures.

We would argue with Strohman that biotechnology itself may already be embracing some of the approaches to complexity that he glimpses on the horizon. We intend for Nature Biotechnology-in the realm of communicated research -to do the same.

\section{Venturing beyond the US}

Biotechnology Investments Limited (BIL), the largest European specialist biotechnology investment fund, is smart. For the first time in its 16-year history, the majority of its unquoted (privately owned) holdings are not based in the US. On BIL's own valuations, $52.7 \%$ of the value of its private holdings rests in its 12 investee companies in the UK, Australia, Israel, Japan, Eire, France, and Bermuda; only $47.3 \%$ in its 23 US holdings. This is not just a matter of geography: BIL is a British-based fund, but until now, its portfolios have always been predominantly North American. The explanation for this crossover is that BIL can make more money this way.

The simple fact is that it is cheaper for venture capitalists to buy new biotechnology companies outside the US. This is because, outside the US, there are only 6 significant biotechnology venture capitalist groups. Competition within this "club" is much more limited than in the US; entrepreneurs in French or British universities, for example, are less able to shop around, and must give away a larger percentage of their nascent enterprise to raise the same amount of money. From a venture capitalist's point of view, non-US entrepreneurs are cheaper. If US venture investors are serious about getting value for their money, they should be looking outside the US.

Not only that, it is also more profitable for venture capitalists to sell their stakes when a company goes public outside the US. When it comes to biotechnology, the public stock markets in London, Paris, or Sydney are unsophisticated. The value benchmarks are set by the big UK companies and those companies are, generally speaking, still significantly overvalued. European or Australasian investors in quoted stocks don't look across the Atlantic or Pacific oceans for comparisons with US companies that are equivalent in size, intellectual property, or product potential. They might be shocked if they did.

Few investors-venture capitalists or players of public marketsare global players. If investors want to limit their profit potential by restricting their interests geographically, then fine. But that will leave the richest pickings for groups like BIL. 